\title{
Information Structure as a Consequence of Word Order Type*
}

\author{
Susan C. Herring \\ California State University, San Bernardino
}

1.0 A great deal of confusion persists in the linguistic literature regarding the relationship of word order to the pragmatic notions of 'topic' and 'focus'. It is well-known that word order variation may be pragmatically motivated, or more precisely, that topic and focuscreating operations often involve pre- or post-posing elements within a clause or sentence. ${ }^{1}$ Starting with the work on 'functional sentence perspective' by Prague School linguists, and continuing through contemporary generative grammar, a correlation has been noted between 'topic/theme' and sentence-initial position, and 'focus' of a constituent within the 'comment/rheme' by means of rightward movement processes. What is not clear, however, (aside from the obvious problem of what exactly is meant by terms such as 'topic', 'focus', etc. ${ }^{2}$ ) is whether this correlation necessarily holds true for all languages.

The question is obscured by the fact that a number of researchers readily invoke 'initial topic position' and 'final focus position' as explanations for word order variation in the languages they consider, treating these notions as unexamined primitives. The underlying assumption here -- that the answer is already known -- is a dangerous one, in that it diverts attention away from the kind of empirical cross-linguistic research which needs to be done in order to prove or disprove the hypothesis. Other researchers argue for the universality of the order 'topic-comment' on cognitive and functional grounds. Many of the arguments they present are intuitively appealing; for example, the view that topics come first because they relate thematically to the preceding discourse, while new, focused referents appear later, closer to the subsequent discourse in which they play a part (cf. Hetzron 1975).

Yet anyone who has had experience in working with a variety of language types, especially African or Amerindian languages, is most likely aware that such a claim is false. It is simply not the case that all languages put topics first and focus last; some in fact exhibit the inverse order. This raises the question of what we are to make of the naturalness arguments used to argue in favor of the universality of the topic-focus order. Are some languages pragmatically "less natural" than others? Or should the arguments themselves be reconsidered? Even more interesting, perhaps, is the challenge of accounting for the different pragmatic types -- focus-topic, as opposed to topic-focus order -- attested crosslinguistically. Is there any systematic correlation between pragmatic function and word order, and if so, is it possible to make a general descriptive statement regarding it?

2.0 What I wish to suggest is that the favored positions of topic and focus in any given language are determined by a set of functional and strategic principles, some of which make conflicting predictions. By far the most accurate predictor, as I will demonstrate below, is basic word order type, and specifically, the unmarked relative order of subject and verb (i.e. whether a language is SV or VS). The word order principle is not without exceptions, however. Individual languages as well as entire language types deviate significantly from the predicted patterns in ways which suggest that discourse-functional principles (of the sort proposed in support of the universality of the order topic-focus) occasionally prevail.

In what follows, I identify four different principles which have been hypothesized to influence topic/focus order, and evaluate their predictive accuracy by comparing the predictions they make with the attested orderings of topic and focus constituents in thirtysix languages. The first three principles have all been proposed, either explicitly or implicitly, in the linguistic literature; each, I feel, offers an intuitively plausible functional motivation for pragmatic word ordering. ${ }^{3}$ The fourth principle is the basic word order hypothesis mentioned above. The four principles may be stated as follows: 
Principle 1: Given information before new information (Gundel 1988; cf. also Prague School linguists, especially Firbas 1964 on 'communicative dynamism'). The structure of utterances in discourse builds on what is known, adding new information which moves the communication forward.

Principle 2: First things first (Gundel 1988; cf. also the 'newsworthiness' principle, Mithun 1987). Predicts that the most pressing or newsworthy information, including that which is unexpected based on the preceding discourse, will precede less important information in communication.

Principle 3: Discourse iconicity (Hetzron 1975 for focus; Prague School linguists for topic). Information ideally is placed as close as possible to the part of the discourse to which it relates; i.e. sentences start with what has already been talked about, and end with what is to be talked about next.

Principle 4: Word order type (Creider \& Creider 1983; Herring 1989b). Information structure is determined relative to a language's basic word order, as a rhetorical marking strategy. Verb-subject languages tend to order focus (comment) before topic, in contrast with languages of either the SVO or the SOV type.

The first three principles I refer to as 'naturalness' principles, in that they are based on presumed communicative and/or functional naturalness, while the last principle is based on the strategic notion of markedness relative to an accepted norm (in this case, basic word order). The predictions that these principles make regarding the preferred position of topic and focus depend in large part on what exactly is meant by 'topic', and what is meant by 'focus'.

In the present study, I will restrict my observations to two types of topic phenomena -continuous topics, and shifted topics -- and two focus types -- contrastive focus, and presentational focus. ${ }^{4}$ Continuous topics I define as those which carry over from the immediately preceding discourse. They are often pronominalized, or, in some languages, omitted altogether. Shifted topics, on the other hand, are discontinuous, and are often signalled by full lexical NPs and/or by topicalizing expressions such as as for $X, \ldots$ or $X$, on the other hand, ..., etc. As for the two types of focus, contrastive focus highlights a constituent within what is usually considered the 'comment' portion of an utterance, typically in contradistinction to a parallel constituent in a previously-uttered (or implied) clause; an example is an expression introduced by an 'it'-cleft in English, as in It's John (not Sidney) that I love. Presentational focus involves the introduction of a referent into a (typically, narrative) discourse; a classic example is an English sentence of the type: Once upon a time, there was a beautiful princess. In this paper I leave aside the more general question of what the two topic types and the two focus types have in common; that is, how we might subsume the subtypes into broader definitions of the terms 'topic' and 'focus'.

It is essential to distinguish subtypes of topic and focus in order to determine whether each presents information which is 'given' or 'new'. I understand 'given information' to be that which the speaker may reasonably expect the hearer to be able to access at a particular point in the discourse, based on the situational context and what has been previously said. It is misleading to state (as is often done) that topics in general represent given information; topics are given if they are thematically continuous, but not if they are new or shifted topics. Similarly, the information status of contrastive focus and presentational focus differs, in that arguments presented for the first time (e.g. as participants in a narrative) are completely new, while contrastively focused arguments are already explicitly or implicitly present in the discourse context (an observation which correlates with their tendency to be grammatically definite). The information status of each of these functions is summarized in table 1 : 
pragmatic function: information status:

\begin{tabular}{|l|l|}
\hline Continuous topics & given \\
\hline shifted topics & new (or reactivated) \\
\hline contrastive focus & given (or implied) \\
\hline presentational focus & new \\
\hline
\end{tabular}

Table 1: Information status of topic and focus sub-types

The four principles listed above make predictions with regard to the position each of the pragmatic functions will favor; that is, whether they will come early or late in the sentence, and whether they will condition pre- or post-posing in marked cases. These predictions are charted in table 2:

\begin{tabular}{|l|l|l|l|l|}
\cline { 2 - 5 } \multicolumn{1}{c|}{} & Principle 1 & Principle 2 & Principle 3 & $\begin{array}{c}\text { Principle 4 } \\
\text { SV/VS }\end{array}$ \\
\hline contin. topic & pre- & post- & pre- & pre-/post- \\
\hline shifted topic & post- & pre- & [pre-] & pre-/post- \\
\hline contr. focus & pre- & pre- & pre- & post-/pre- \\
\hline present. focus & post- & [post-] & post- & post-/pre- \\
\hline
\end{tabular}

Table 2: Predictions made by principles 1-4

Looking down each column vertically, we can see that Principle 1, the given-before-new principle, predicts that given information, such as that in continuous topics and contrastive foci, may be preposed, e.g. in case the targeted element does not already appear in the unmarked topic/focus position in the sentence, or for special emphasis. ${ }^{5}$ Shifted topics and presentational foci, which are new or otherwise inaccessible in the local discourse context, should occur later in the sentence, according to this principle. ${ }^{6}$ Principle 2 , the first-things-first principle, predicts that whatever is most important for the listener to know in order to correctly interpret the sentence should come first; thus constrastive information, such as that expressed in topic shifts and contrastive foci, is likely to be fronted, while predictable, thematic information, such as continuous topics, should occur late. Predictions given in square brackets in the table are those that I feel the principle makes only weakly; thus Principle 2 sanctions the post-posing of presentational foci (in that they are not vital to establishing the interpretation of the rest of the sentence), but does not necessarily restrict them from occurring earlier. Post-posing of presentationally focused arguments is most strongly predicted by Principle 3, the discourse-iconic principle. It is a typical discourse strategy for arguments to be first presented, then commented upon in the following sentence or clause (see Lambrecht 1986); moving them rightward thus places them closer to the context in which they most logically figure. Continuous topics and contrastive foci, on the other hand, are more naturally associated with the previous discourse, and for them pre-posing is predicted. As for shifted topics, they should occur early in case they are contrastive, but the discourse-iconic principle is neutral as to their position if they are new. (In practice, this should depend on whether the new topic is continued in the subsequent utterance or not.) Looking across the table horizontally, we see that the three naturalness principles make conflicting predictions with regard to continuous and shifted topics, but are unanimous in predicting that contrastive focus should appear early in the sentence and presentational focus, late. Thus we might expect that languages, if indeed they are influenced in their pragmatic use of word order by naturalness considerations of this sort, would universally pre-pose contrastive foci and post-pose presented referents, but that there would be some cross-linguistic variability with regard to the positions of the two types of topic. 
In contrast with these three principles, the word order principle makes predictions based not on assumed naturalness, but rather on observed tendencies in how certain languages order topic and focus. Creider (1975) was, to my knowledge, the first to note that in verb-initial languages, the focus, or 'theme', precedes the topic. His observations were based on several VSO African languages of the Nilotic family. Tomlin and Rhodes (1979) made a similar observation for Ojibwa, which has VOS order. In a recent study (Herring 1989b), I compared and contrasted preferred topic and focus positions in 17 languages, ${ }^{7} 11$ of which had VS order, and found that basic word order -- specifically, the order of the subject in relation to the verb -- accurately predicted the order of topic and focus in every case. Generalizing from observations made for a limited set of languages by Creider, Tomlin and Rhodes, and myself, then, the word order principle predicts that topics of either type will be pre-posed in SV languages but post-posed in VS languages, while foci will be post-posed in SV languages but pre-posed in VS languages. The mechanism underlying this principle is presumably a strategic one, based on the goal of achieving salience by the use of word orders which are marked relative to the pragmatically "neutral" order (however this latter is to be defined).

It is evident from table 2 that no two of the four principles make exactly the same set of predictions. Only the word order principle, Principle 4, groups together the two topic categories and the two focus categories. If this principle turns out to represent a general cross-linguistic pattern, it would support the notions of topic and focus as unitary and distinct functional categories in language. Note also that it is only the word order principle which predicts that different languages will order topic and focus differently; the others, based as they are on considerations of functional and communicative naturalness, predict that all languages will prefer a single ordering. (This is true regardless of what one interprets the predictions they make to be.)

3.0 The second part of the analysis consists of comparing the predictions made by the four principles with the attested patterns of topic/focus order in a sampling of typologically diverse languages. I examined data from primary and secondary sources for 36 languages, listed in appendix 1. The languages represent five major word order types: SVO, SOV, VSO, VOS, and OVS; 8 also included are several languages considered to have "free" word order. The procedure I followed in gathering information from secondary sources was to count as evidence of a particular correlation 1) example sentences in which a construction in the language was consistently glossed in English by means of explicit shifted topic expressions such as $A s$ for $X, \ldots$ or contrastive focus expressions such as clefts; 2) example sentences for which enough contextual information was provided to determine whether a topic was continuous or shifted, and whether a nominal referent was being presented as a new focus of information (e.g. in narrative texts); and/or 3) explicit remarks on the part of the authors to the effect that a particular word order marks a particular function in the language in question, taking into account differences in terminology, and excluding claims which did not appear to be supported by the actual data presented. There are several obvious problems with this method, not the least of which is that it was not possible to identify all four of the topic/focus subtypes for every language, nor to determine the relative frequency of any construction's use. ${ }^{9}$ Even given these inadequacies, however, a number of very distinct patterns emerge, which strongly suggest some sort of overall typological consistency. I will summarize these patterns briefly.

Ignoring, for the moment, individual languages which display exceptions (indicated by asterisks in appendix 1), we may state that topic/focus positions vary predictably according to a language's basic word order type. SVO languages as genetically diverse as English, Mandarin, and Luo all agree in their preference for placing topics of both types in initial -subject -- position, and focused arguments in post-verbal -- object -- position. ${ }^{10} \mathrm{SOV}$ languages such as Turkish, Tamil, and Japanese also show a preference for initial topics, but due possibly to a constraint of strict verb-finality in many SOV languages, focus 
position is immediately pre-, rather than post-verbal. ${ }^{11}$ Thus SOV languages also evidence a correlation between topic and subject, and focus and object. Elements which appear to the right of the finite verb in such languages are backgrounded intonationally and pragmatically, and tend to express highly predictable, thematic information; accordingly, continuous topics may appear sentence-finally. This is also true for SVO languages; consider the English example: He's an idiot, that guy. Thus languages of both the SVO and the SOV types generally support the claim that topic precedes focus. We may compare the findings for these two language types with the specific predictions made by our four strategic principles, as given in table 2 . This is illustrated in table 3:

\begin{tabular}{|c|c|c|c|c|c|}
\hline & Results: & \multicolumn{4}{|c|}{ Support predictions made by: } \\
\hline & SVOSOV & Principle 1 & Principle 2 & Principle 3 & Principle 4 \\
\hline contin. topic & $\begin{array}{c}\text { pre-/pre } \\
\text { (post-/post-) }\end{array}$ & $\begin{array}{l}\text { YES } \\
\text { (NO) }\end{array}$ & $\begin{array}{c}\text { NO } \\
\text { (YES) }\end{array}$ & $\begin{array}{l}\text { YES } \\
\text { (NO) }\end{array}$ & $\begin{array}{l}\text { YES } \\
\text { (NO) }\end{array}$ \\
\hline shifted topic & pre-/pre- & No & YES & [YES] & YES \\
\hline contr. focus & $\begin{array}{l}\text { post- } / \text { post-" } \\
\text { (pre- } /)\end{array}$ & $\begin{array}{c}\text { NO } \\
\text { (YES) }\end{array}$ & $\begin{array}{l}\text { NO } \\
\text { (YES) }\end{array}$ & $\begin{array}{c}\text { NO } \\
\text { (YES) }\end{array}$ & $\begin{array}{l}\text { YES } \\
\text { (NO) }\end{array}$ \\
\hline present. foc. & post- $\Gamma^{\prime p}$ post-" & YES & [YES] & YES & YES \\
\hline
\end{tabular}

Table 3: Comparison of predictions with results for SV languages

Looking across table 3, we see that the fronting of continuous topics is correctly predicted by all but principle 2 , the first-things-first principle (which does, however, justify post-posed, backgrounded topics of the type mentioned above). Initial position for shifted topics is accurately predicted by all but principle 1, the given-before-new principle. Only principle 4 , the word order principle, accurately predicts that contrastive focus may be postposed (as in the case of WH-cleft constructions), while the post-posing of presented arguments is consistent with the predictions of all four principles. Reading the table vertically, we see that the word order principle most accurately predicts the basic ordering of pragmatic functions of all four types, followed by the discourse-iconic principle, with the given-before-new and the first-things-first principles right in only half of the cases.

What then, of languages in which the order of subject and verb is reversed? A general tendency may be identified for VSO languages, in which focused elements of both types may be moved into pre-verbal position. ${ }^{12}$ This is true for example for Jacaltec, Biblical Hebrew, and Nandi. In Podoko, on the other hand, the position of greatest focus is immediately post-verbal, although if anything other than the subject is focused, leftward movement is still required. This situation is in some ways analagous to that of SOV languages with a rigid verb-final constraint, in that the initial or final verb acts as a barrier to focus movement, such that the focused element moves as far as it can in the direction of the verb before being blocked. As for topics, the two subtypes split, with continuous topics appearing post-verbally, and shifted topics pre-verbally, in virtually all of the VSO languages in my sample. VOS languages such as Ojibwa and Malagasy pattern the same as do VSO languages; in both, focused elements and shifted topics may be pre-posed, while continuous topics remain post-verbal. The OVS languages in the sample, Hixkaryana and Makushi, also pattern like verb-initial languages for all four functions, as do the three "free" word order languages discussed in Mithun (1987), which exhibit a statistical preference, albeit slight, for OVS order. Generalizing, we may state that in languages in which the basic order is verb-subject, the order focus-topic is preferred, unless the topic is new or contrastive, in which case, it appears initially. These results are matched with the predictions of the four principles in table 4 below: 
Results:

Support predictions made by:

\begin{tabular}{|l|c|c|c|c|c|}
\cline { 2 - 6 } \multicolumn{1}{c|}{} & $\begin{array}{c}\text { VSO/VOS/ } \\
\text { OVS }\end{array}$ & Principle 1 & Principle 2 & Principle 3 & Principle4 \\
\hline contin. topic & post & NO & YES & NO & YES \\
\hline shifted topic & pre- & NO & YES & [YES] & NO \\
\hline contr. focus & $\begin{array}{c}\text { pre- } \\
\text { ("pre-") }\end{array}$ & YES & YES & YES & YES \\
\hline present. foc. & pre- & NO & (YES) & (YES) & (YES) \\
\hline
\end{tabular}

Table 4: Comparison of predictions with results for VS languages

It can be seen from table 4 that the three naturalness principles fare no better or worse for VS languages than for SV languages -- that is, they make correct predictions only about half the time. The word order principle makes one incorrect prediction here, namely that shifted topics, like continuous topics, should be post-posed. Even given this, it is by far the most accurate predictor of the actual orderings of any of the principles considered.

However it is not the case that naturalness principles have nothing to say about the pragmatic functions of word order. Languages of all types are consistent in putting shifted topics first, even against the predictions of the word order principle in VS languages. This ordering is conditioned most significantly by the first-things-first principle, and is probably the one true universal of pragmatic ordering. When the topic of a sentence shifts or is otherwise unpredictable, it must be explicitly stated at the outset, lest the hearer misinterpret what the sentence is about. (Similar observations have been made by Creider \& Creider (1983), Gundel (1988), and Mithun (1987).)

Another area in which naturalness principles hold sway is with contrastive focus. Post-posed constrastive focus such as is found in SV languages is counter-indicated by all three naturalness principles. While on the one hand this is strong evidence in favor of the word order hypothesis, it is also not without exception. As an example, consider the problem of it-clefts in English, the counterpart of which is found in numerous SVO languages. By one analysis, it-cleft constructions such as It's John that I love pre-pose the object NP, John, whereas by another analysis, It's John is a type of presentative construction in which the order of subject and verb has been inverted, making John the focus of a post-posing process. Regardless of how one resolves this controversy, there is evidence from other SVO languages which is even more problematic. In Kru (Marchese 1983), the focused element in it-type clefts appears in sentence-initial position, followed by a copula functioning as focus marker. Thus there is no possible analysis whereby such focused elements could be viewed as anything other than fronted. Similarly, nominalized clefts (e.g. the one who was sacrificed was Abraham) occur more often in "reversed" order (ABRAHAM was the one who was sacrificed) -- that is to say, with the focused element first -- than in normal order in Lele, according to Simons (1982). This suggests that there is, in the case of SV languages, a tension between the word order principle and the naturalness principles with regard to contrastive focus, and that it is not always the word order principle which prevails. Other exceptions can be explained similarly, i.e. as the result of a conflict between predictions made by different functional principles.

4.0 If, as these results indicate, word order type is a valid predictor of pragmatic ordering cross-linguistically, the question naturally arises as to what motivates the strategy in the first place. Although in the present paper I have made a heuristic division between the word order principle on the one hand, and commonly invoked naturalness principles on the other, I do not intend to imply by this that the word order principle is in any way unnatural. On the contrary, given its apparently universal distribution, we must suspect that it is driven by basic and easily-accessible strategic principles. 
I have suggested here that the notion of pragmatic markedness plays a key role in the analysis of the word order principle. As a strategy which produces marked word orders to express emphasis or contrast, it is iconic, in that it draws attention to itself by virtue of its deviation from the expected norm. This explanation leaves unanswered, however, the question of why the strategy takes as its point of departure the relationship between subject and verb, rather than that between verb and object (as in traditional Greenbergian typological analysis) or between subject and object.

The answer lies, I believe, in the interaction of two asymmetries in discourse patterns. First, there is a well-attested cross-linguistic correlation between grammatical subject and pragmatic topic; subjects are prominent on hierarchies of animacy and agentivity (Silverstein 1976), while topics are prominent in discourse as (typically) animate and agentive thematic participants (Givon 1983). The correlation between direct object and focus is much weaker, however. First, not every sentence has an object, but it may still have a focus, since focus may be a property of predicates and of sentences as a whole, as well as of 'narrow' focus nominal arguments (Lambrecht 1986). From the point of view of discourse, although DuBois (1987) characterizes direct object as a preferred argument role for the introduction of new discourse referents, Herring (1989a) presents evidence to the effect that intransitive subjects are significantly more strongly preferred in this function, particularly when the referent is animate. This further weakens the correlation of direct object with pragmatic focus. On the basis of this asymmetry, then, we may speculate that a language user is more likely to notice a correlation between grammatical argument position and pragmatic function in the case of subject/topic, where a stronger correlation exists. Following this line of reasoning further, the language user then generalizes canonical subject position (whatever it happens to be in his or her language) as topic position, allowing for the possibility of topicalizing arguments other than grammatical subject. As for what determines focus position, it is likely that the relative complementarity of the two pragmatic functions, and the fact that it is sufficient to order them with respect to one another, combine to select a focus position which requires movement (in those cases when movement is required) in the direction opposite of that for topicalization. This tendency is no doubt supported by the weaker, but still perceptible, correlation between 'new' focused referents and direct object position.

The second asymmetry involves the discourse motivations for creating marked word orders. In narrative discourse, thematic participants (i.e. referents which persist or recur as utterance topics across continuous stretches of discourse) are typically animate and agentive, as mentioned above, and function as the grammatical subject of the clause in which they appear. While this pattem is the most statistically frequent, a different situation nevertheless arises when these same referents are introduced into the discourse for the first time. At this moment, they are not yet topics; rather, they are typically accorded some sort of presentational focus. In order to focus a subject NP, however, it is necessary to either mark it as exceptional by means of intonation or explicit focus morphology, or else to move it out of canonical topic position. In such cases, since presentational verbs tend to be intransitive (be, live, stand, sit, come, go, etc.), the most consistently available word order device is one which permutes subject and verb relative to one another, as in Once upon a time, there was a princess -type sentences in English. Thus the marked order of subject and verb addresses a clear functional need. The same is not true of the relation of verb to object. A parallel explanation would require us to identify a strong discourse motivation for topicalizing objects, yet it is difficult to imagine what such a motivation might be. To the contrary, topicalized objects (with the possible exception of objects promoted to subject via passivization) are rare in narrative, no doubt due to the predominance of the tendency described above for topics to be expressed grammatically as subjects. Add to this the observation that referents occurring in object position are frequently inanimate props which lack thematic persistance, and the apparent motivation for topicalizing objects decreases even further. This leaves us with the third logical possibility mentioned above, namely that the word order principle takes as its point of reference the relative order of subject and 
object. While many of the word order permutations considered do in effect reverse the order of subject and object, direct objects -- overt or otherwise -- are often unavailable, since actual discourse makes use of intransitive as well as transitive verbs (Herring 1988 notes that $70 \%$ of all finite verbs in a Tamil oral narrative corpus are intransitive). Most sentences have a predicate, however. If the relationship of subject to object were the primary determinant of the pragmatic word order strategy described here, it would require speakers to ignore a consistently available relationship (subject/predicate) in favor of one that is attested only part of the time. This seems inherently more difficult to motivate, and in the absence of any supporting evidence, I dismiss this possibility as well. Thus not only is the correlation of subject to topic more salient than the correlation of object to focus, but there is a clear discourse motivation, in narrative at least, for permuting the order of $S$ and $\mathrm{V}$, whereas in the case of the relationship of $\mathrm{O}$ to $\mathrm{V}$, or $\mathrm{S}$ to $\mathrm{O}$, such a motivation is lacking. Both asymmetries point to the centrality of $S: S$ has a clearly identifiable pragmatic function, and the relationship of $S$ to $V$-- the two sentence elements which are typically minimally present -- allows for the inference of relative order. While these observations are necessarily speculative and leave many particulars of the process unarticulated, they suggest, I believe, some plausible ways in which the word order principle can be motivated by relatively simple and universal mechanisms.

5.0 I conclude with an appeal to linguists interested in topic/focus phenomena and/or linguistic typology to take up the challenge of verifying -- or disproving -- the analysis presented here. The program, as I see it, will crucially involve careful investigation of discourse-pragmatic patterns in less familiar languages, especially those in which the basic order is VS. The full range of topic and focus subtypes needs to be considered as well, if we are to arrive at an adequate understanding of the nature of these categories, and of their typological correlates. We have nothing to lose by such an effort, since no other existing account is able to explain cross-linguistic pragmatic word order variation. We stand to gain a powerful predictive tool.

\section{ENDNOTES}

* I am grateful to John Paolillo, Eric Pederson, and Randy LaPolla for comments and discussion which contributed significantly to the present paper.

1 Languages also employ other means of indicating topic/focus functions, e.g. intonation and explicit topic/focus morphology, but due to space limitations, these will not be considered further here.

2 For example, in the literature on Philippine languages, the term 'focus' refers to a grammatical category which is definite, and which more closely resembles the notion of topic in non-Philippine studies, while the term 'topic' is used to describe elements in contrastive focus (cf. Naylor 1975).

3 Other functional principles have no doubt been proposed, or will be proposed in the future, which might profitably be included in a comparative endeavor of this sort as well. Herring (1989b) mentions several cognitive principles hypothesized to influence topicfocus order, this is clearly an area requiring further study.

4 There are other types of focus that would need to be included in a broader study, for example predicate focus and sentence focus (cf. Lambrecht 1986), and within the narrow focus range, WH- focus. It is also possible that the set of phenomena I have grouped together under 'contrastive focus' does not really constitute a functionally homogenous category; we might, for instance, wish to separate out WH- type clefts from it-type clefts, if it could be determined that there was a consistent difference in the functions of the two across languages which have both types. 
5 It is important to note that in no language would we predict that pre-posing or postposing is essential to the expression of topic or focus functions. Rather, movement operations constitute a marked option which a language may have available, and which may be strongly favored under certain grammatical-pragmatic conditions. For example, topicalized objects are more likely to be moved than topicalized subjects, since in most languages, the $S$ position is the normal (unmarked) topic position, while the $O$ position is associated with focus. For similar reasons, focused subjects appear to condition movement more often than focused objects.

6 Jeanette Gundel (personal communication) disagrees that the given-before-new principle makes the prediction that shifted (new) topics would be post-posed, on the grounds that the topic, even if shifted, should always be considered 'given' relative to the comment or focus. This view appears to confuse the topic-comment relationship with the given-new status of referents. While it is indeed the case that no language (to my knowledge) postposes shifted topics -- a fact which I account for in terms of the overriding of the word order principle by the naturalness principles -- I believe that it is, at least, theoretically possible. It is certainly possible for topics to be new, and comments given. I have in mind discourses such as the following:

1) A: I'm so proud of my David; he just graduated from college magna cum laude. B: Now my Julie, she graduated from college magna cum laude. And she got a job working for a senator in Washington!

2) A: I'm beat. I really need to get some sleep.

B: You need to get some sleep? I need to get some sleep!

In B's initial utterance in example 1, the comment (graduated from college magna cum laude) is given; what is new is the shift in topic (from my David/he to my Julie/she). Similarly in 2, B's contrastive assertion I need to get some sleep relates a given comment to a new topic. (Notice that these constructions cannot be analyzed as contrastive focus constructions; the corresponding it-cleft focus constructions force a narrower interpretation; e.g. It's my Julie who graduated from college magna cum laude seems to deny that David graduated from college magna cum laude). New topics with given comments appear to be characteristic of a "one-upmanship" discourse style.

7 The 17 languages surveyed in Herring (1989) include Ojibwa, but do not include any of the languages discussed by Creider, in that I was not aware of Creider's work when I undertook my initial study.

8 As of this writing, I have not been able to gather enough information on pragmatic ordering in OSV languages to include them as a category.

9 I excluded from a larger sample those languages for which fewer than 3 of the 4 topic/focus sub-types could be determined from the available sources.

10 It is not uncommon for SVO languages to have two types of contrastive focus constructions, as exemplified by the two types of cleft (WH- and it-) in English. In these languages, one construction post-poses the focused element, while another appears to prepose it; hence the 'pre-' in parentheses in table 3.

11 I designate contrastive focus in these languages as "post"-posing, since in the case of all but direct object focus, rightward movement is involved. Interestingly, the strict verbfinal constraint disappears in nominalized predicate constructions in SOV languages such as Tamil and Sinhala, where the focused constituent is preferentially post-verbal, as in the Sinhala example below (Gair 1970; 136):

hamadaama putaa kanne nikan bat
every-day son eat-pr-emph plain rice
'It is plain rice (that) the son eats every day.' 
12 This observation requires further verification for presentational focus, however, in that presentational data are rare in my VSO language sources.

\section{Appendix 1: Languages included in sample}

(* indicates deviation from word order principle)

SY0

English

Spanish (Bolinger 1952)

French (Lambrecht 1986, 1987)

Mod. Hebrew (Berman 1980; Givón 1976)

Mandarin (Li \& Thompson 1981)

Luo (Creider \& Creider 1983)

Kimatuumbi (Odden 1984)

Pulaar (Fagerberg 1983)

Lele (Simons 1982)

Kru* (Marchese 1983)

SOY

Sinhala (Gair 1970, 1986)

Turkish (Erguvanli 1984)

Japanese (Hinds 1973; Kuno 1972)

Korean (Kim 1985, 1988)

Hungarian (Kiss 1977)

Sherpa (Givon 1984)

"Free" Word Order: topic-focus

Gavião (SOV/SVO) (Stute 1986)

Xavante* (OSV/SOV) (Burgess 1986)
VSO

Jacaltec (Craig 1977)

Biblical Hebrew (Givón 1984)

Welsh (Williams 1980)

Irish (Bammesberger 1982)

Tagalog (Naylor 1975)

Nandi (Creider 1975; Cr. \& Creider 1983)

Podoko (Jarvis 1981)

Turkana (Dimmendaal 1983)

Classical Arabic* (Beeston 1970, 1974)

YOS

Ojibwa (Tomlin \& Rhodes 1979)

Malagasy (Keenan 1976)

OVS

Hixkaryana (Derbyshire 1977)

Makushi (Derbyshire \& Pullum 1981)

"Free" Word Order: focus-topic

Cayuga (OVS) (Mithun 1987)

Ngandi (OVS) (Mithun 1987)

Coos (OVS) (Mithun 1987)

Ute (SOV/OVS) (Givón 1984)

\section{REFERENCES}

Bammesberger, Alfred. 1982. Essentials of Modern Irish. Heidelberg: Carl Winter.

Beeston, A.F.L. 1970. The Arabic Language Today. London: Hutchinson.

Beeston, A.F.L. 1974. "Embedding of the theme-predicate structure in Arabic." Language 50.3 ; 474-477.

Berman, Ruth. 1980. "The case of an (S)VO language." Language 56:4; 759-776.

Bolinger, Dwight. 1952. "Linear modification." Publications of the Modern Language Association 67; 1117-1144.

Burgess, Eunice. 1986. "Focus and topic in Xavante." In Sentence Initial Devices, Joseph Grimes (ed.); 27-41. Dallas: Summer Institute of Linguistics.

Craig, Colette G. 1977. The Structure of Jacaltec. Austin: University of Texas Press.

Creider, Chet A. 1975. "Thematization and word order." Paper presented at the annual meeting of the Linguistic Society of America.

Creider, Chet A. and Jane T. Creider. 1983. "Topic-comment relations in a verb-initial language." Journal of African Languages and Linguistics 5; 1-15. 
Derbyshire, Desmond. 1977. "Word order, universals, and the existence of OVS languages." Linguistic Inquiry 8.3; 590-597.

Derbyshire, Desmond \& Geoffrey K. Pullum. 1981. "Object-initial languages." IJAL 47.3; $192-214$.

Dimmendaal, Gerrit J. 1983. "Turkana as a verb-initial language." Journal of African Languages and Linguistics 5; 17-44.

DuBois, John W. 1987. "The discourse basis of ergativity." Language 63.4; 805-855.

Erguvanli, Eser E. 1984. The Function of Word Order in Turkish Grammar. University of California Publications in Linguistics, Vol. 106. Berkeley and Los Angeles: University of Califormia Press.

Fagerberg, Sonja. 1983. "Discourse Strategies in Pulaar: the use of focus." Studies in African Linguistics 14.2; 141-157.

Firbas, Jan. 1964. "On defining the theme in functional sentence analysis." Travaux Linguistiques de Prague 1; 225-240.

Gair, James W. 1970. Colloquial Sinhalese Clause Structures. Janua Linguarum Series Practica 83. The Hague: Mouton.

Gair, James W. 1986. "Sinhala focused sentences: naturalization of a calque." In Structure, Convergence and Diglossia, Bh. Krishnamurti (ed.); 147-164. Delhi: Motilal Banarsidass.

Givon, Talmy. 1976. "On the V-S word-order in Israeli Hebrew: pragmatics and typological change." In Studies in Modern Hebrew Syntax and Semantics, P. Cole (ed.); 153-181. Amsterdam: North Holland.

Givón, Talmy. 1983. Topic Continuity in Discourse: A Quantitative CrossLanguage Study. Amsterdam: John Benjamins.

Givón, Talmy. 1984. Syntax: A Functional-Typological Introduction. Vol.1. Amsterdam: John Benjamins.

Gundel, Jeanette K. 1988. "Universals of topic-comment structure." In Studies in Syntactic Typology, Michael Hammond, Edith Moravcsik and Jessica R. Wirth (eds.); 209-239. Amsterdam: John Benjamins.

Herring, Susan C. 1988. "Aspect as a discourse category in Tamil." BLS 14; 280-292.

Herring, Susan C. 1989a. "Verbless presentation and the discourse basis of ergativity." CLS 25; 123-137.

Herring, Susan C. 1989b. "Is sentence-final 'focus' position universal?" Paper presented at the annual meeting of the Linguistic Society of America.

Hetzron, Robert. 1975. "The presentative movement, or why the ideal word order is V.S.O.P." In Word Order and Word Order Change, Charles N. Li (ed.); 347-388. Austin: University of Texas Press.

Hinds, John. 1973. "Theme and rheme in Japanese." Seishin Studies 41; 1-13.

Jarvis, Elizabeth. 1981. "Some considerations in establishing the basic word order of Podoko." Studies in African Linguistics 12.2; 155-167.

Keenan, Edward L. 1976. "Remarkable subjects in Malagasy." In Subject and Topic; Charles N. Li (ed.); 337-384. New York: Academic.

Kim, Alan Hyun-Oak. 1985. "The function of linear order in Korean syntax." Harvard Studies in Korean Linguistics; 154-167. Cambridge: Harvard University. Kim, Alan Hyun-Oak. 1988. "Preverbal focusing and type XXIII languages." In
Studies in Syntactic Typology, Michael Hammond, Edith Moravcsik and Jessica R. Wirth (eds.); 147-169. Amsterdam: John Benjamins.

Kiss, H. 1976. "Topic and focus in Hungarian syntax." Montreal Working Papers in Linguistics 8; 1-42.

Kuno, Susumo. 1972. "Functional sentence perspective: a case study from Japanese and English." Linguistic Inquiry 3; 269-320.

Lambrecht, Knud. 1986. "Topic, focus, and the grammar of Spoken French". Ph.D. dissertation, University of California, Berkeley. 
Lambrecht, Knud. 1987. "On the status of SVO sentences in French discourse". In Coherence and Grounding in Discourse, Russell S. Tomlin (ed.); 217-261. Amsterdam: John Benjamins.

Li, Charles N. \& Sandra A. Thompson. 1981. Mandarin Chinese: A Functional Reference Grammar. Berkeley and Los Angeles: University of California Press.

Marchese, Lynell. 1983. "On assertive focus and the inherent focus nature of negatives and imperatives: evidence from Kru." Journal of African Languages and Linguistics 5; 115-129.

Mithun, Marianne. 1987. "Is basic word order universal?" In Coherence and Grounding in Discourse, Russell S. Tomlin (ed.); 281-299. Amsterdam: John Benjamins.

Naylor, Paz B. 1975. "Topic, focus, and emphasis in the Tagalog verbal clause." Oceanic Linguistics 14; 12-79.

Odden, David. 1984. "Formal correlates of focusing in Kimatuumbi." Studies in African Linguistics 15.3; 225-299.

Silverstein, Michael. 1976. "Hierarchy of features and ergativity." In Grammatical Categories in Australian Languages, Robert Dixon (ed.); 112-171. New York: Humanities Press.

Simons, Pamela. 1982. "Nè...ba marking in Lele: a cleft construction?" Studies in African Linguistics 13.3; 217-229.

Stute, Horst. 1986. "Constituent order, cohesion and staging in Gavião." In Sentence Initial Devices, Joseph Grimes (ed.); 7-25. Dallas: Summer Institute of Linguistics.

Tomlin, Russell and Richard Rhodes. 1979. "An introduction to information distribution in Ojibwa." CLS 15; 307-320.

Williams, Stephen J. 1980. A Welsh Grammar. Cardiff: University of Wales Press. 